The determination of the factors involved in the establishment of a production "diagnosis " can be made on the basis of the following four main analyses :

I. Age at first farrowing (it must be located between 330 and 380 days) ;

2. Structure and demography of the herd;

3. Prolificacy (piglets born, lost and weaned);

4. Fertility.

Fertility disturbances might be disguised by a systematic elimination of sows which return into heat. It is therefore necessary to simultaneously observe the weaning-conception interval and the percentage of last litters.

\title{
Factors of productivity in sow herds
}

\author{
O. TEFFENE and J. VANDERHAEGEN
}

Institut technique du Porc,

149, we de Bercy,

75579 Paris Cedex 12

On the basis of $45 \mathrm{I}$ sow production units located in all regions of France and for the most part members of pig producer associations, a statistical analysis was made of the annual average values obtained in each herd with respect to the main technical aspects of sow productivity.

Analysis of the significant correlation coefficients between the $2 \mathrm{I}$ variables determined, reveals the existence of two distinct groups :

\section{a) Characters including results and techniques (see the figure) \\ b) Structural Characters \\ (see the figure)}

The correlations are low between these two groups except for the rate of first litters and the age of the herd, both related together, as well as to data variables and to structure variables.

Eight independant factors, accounting for 80 p. Ioo of the total variance were identified by a factorial analysis in main components :

- rearing conditions, with a major incidence on piglet losses,

- prolificacy,

- herd structure,

- unproductive periods,

- herd size,

- growth,

- renewal,

- weaning.

There are many factors of heterogeneity and therefore each one only represents a slight significant part of the total variation. 
The productivity $\mathrm{P}$, i.e. number of piglets weaned per sow and per year, estimated by progressive multiple regression from the variables, is expressed by :

$$
\mathrm{P}=8.8 \mathrm{I} 7+\mathrm{I} .735 x_{1}-0.204 x_{2}-0.092 x_{3}-0.09 \mathrm{I} x_{4}(\mathrm{R} \ldots 0.98 \mathrm{I})
$$

$x_{1}=$ mean prolificacy,

$x_{2}=$ losses from birth to weaning (p. Ioo),

$x_{3}=$ weaning-conception interval (days),

$x_{4}=$ weaning age (days).

Thus, the gain of one piglet weaned per sow and per year can be obtained in the following way :

- either by increasing the prolificacy by 0.58 piglet at birth

- or by reducing,

either the losses from birth to weaning by $4.9 \mathrm{p}$. Ioo

or the weaning-conception interval by 10.9 days

or the age at weaning by 10.9 days.

For one week gained at each reproductive cycle, the numerical productivity is improved by 0.64 piglet. The improvement of piglet production depends on a series of coherent measures and the possible margin of progress remains large in the French pig herds.

\title{
Effects of month of farrowing, litter order and genetic type of the mother on the components of sow productivity in French farms
}

\author{
C. IEGAULT, J. DAGORN* and D. TASTU \\ Station de Génétique quantitative et appliquée, I. N.R. A., C. N.R. Z., \\ 78350 Jouy en Josas \\ * Institut technique du Porc, \\ 149, rue de Bercy, \\ 75579 Paris Cedex 12
}

Data collected in lirench farms were analysed in order to estimate the effects of month of farrowing, litter order and genetic type of the female on the components of sow productivity.

In the first study, $17660 \mathrm{I}$ litters werc classified according to their month of birth (I 2 levels), Iitter order ( 7 levels) and genetic type of the sow (4 levels) and submitted to a least squares analysis. The greatest litter sizes at birth were observed in January $(0.26$ piglet more per litter than in July and August) ; Inversely, the greatest litter sizes at weaning corresponded to birth in June (o.34 piglet more per litter than in December). Weaning-conception interval was I I days longer when farrowing took place in June as compared to farrowing in Jecember. Moreover, this interval was 7 days longer in primiparous than in multiparous sows.

In the second study, 2 I I I litters were classified according to herd (88 levels), litter order (6 levels) and genetic type of the sow (Large White, Large White $\times$ Landrace, Landrace $\times$ Large White and Landrace) and submitted to the same analysis as previously. At least two genetic types 